Article

\title{
A Novel Method for Culturing of Leptothrix sp. Strain OUMS1 in Natural Conditions
}

\author{
Tomoko Suzuki ${ }^{1}$, Hiromichi Ishihara ${ }^{1}$, Mitsuaki Furutani ${ }^{1}$, Tomonori Shiraishi ${ }^{2}$, \\ Hitoshi Kunoh ${ }^{1}$ and Jun Takada ${ }^{1, *}$
}

1 Department of Material Chemistry, Graduate School of Natural Science and Technology, Okayama University, Okayama 700-8530, Japan; E-Mails: suzukito@cc.okayama-u.ac.jp (T.S.);

hishihara@cc.okayama-u.ac.jp (H.I.); dns421306@s.okayama-u.ac.jp (M.F.);

hkunoh@cc.okayama-u.ac.jp (H.K.)

2 Laboratory of Plant Pathology, Graduate School of Environmental Science, Okayama University, Okayama 700-8530, Japan; E-Mail: tomoshir@cc.okayama-u.ac.jp

* Author to whom correspondence should be addressed; E-Mail: jtakada@cc.okayama-u.ac.jp;

Tel.: +81-86-251-8107; Fax: +81-86-251-8087.

Received: 8 February 2012; in revised form: 23 March 2012 / Accepted: 15 May 2012 /

Published: 23 May 2012

\begin{abstract}
Although some strains of Leptothrix spp. isolated from aquatic environments have been characterized by culturing them in laboratory conditions, they often show morphological and chemical features distinct from those found in natural environments. To resolve this discrepancy, a novel cultivation method was devised for culturing such strains in natural groundwater. Leptothrix sp. strain OUMS1 was pre-cultured in a medium lacking Fe for 2 days, and then injected into a small dialysis tube bag and immersed in a container with continuously flowing groundwater for 1-3 and 14 days. Microscopic analysis of the initial phase of sheath formation and arbitrary comparisons with medium cultures revealed that in groundwater the surface coat of the sheath comprised much thinner fibrils, and an inner sheath wall that was much thinner and more indistinct compared with medium cultures. These differences were probably attributable to poorer secretion from the cell surface in groundwater conditions. A nutrient-rich medium likely activates cell metabolism and promotes secretion, resulting in a thicker inner sheath wall and thicker outer coat fibrils. Aqueous-phase Fe was deposited on immature sheaths in a similar manner in both cultures. These results indicate that laboratory culture of isolated microbes does not always reflect their characteristics in natural environments.
\end{abstract}


Keywords: Leptothrix sp. OUMS1; novel culturing method in natural groundwater; sheath formation; bacterial carbohydrates; bacterial exudation; deposition of aqueous-phase iron

\section{Introduction}

Some bacteria serve as distinct nucleation sites for mineral authigenesis in situ [1]. The important biogeochemical processes of iron (Fe) and manganese $(\mathrm{Mn})$ deposition in terrestrial and aquatic habitats are often attributed to microbial activity [2]. Bacteria belonging to the Sphaerotilus-Leptothrix group are characterized by the formation of an extracellular microtubular sheath surrounded by a slime layer that is closely associated with the Fe-accumulating and Mn-oxidizing capacities of these organisms in aquatic environments [3]. These properties lead to the formation and accumulation of large amounts of ferric and Mn oxides that are characteristic features of most Leptothrix spp. [4]. The discovery of an ichnite of Leptothrix and associated sheath structures in a geological layer two billion years old [5] tells us that metal-oxidizing bacteria including Leptothrix contribute directly or indirectly in converting aqueous-phase metals such as $\mathrm{Fe}$ and $\mathrm{Mn}$ to solid Fe/Mn oxides for an immeasurably long period of time. The Fe/Mn-depositing bacteria and the unique architecture of their extracellular structures have attracted attention since the nineteenth century [3], and the body of evidence and hypotheses related to their architecture and chemical and physical characteristics have been summarized and commentated on in a number of reviews [1,3,4,6,7]. Nevertheless, little is known about the mechanisms of initiation and construction of such metal-depositing structures as well as their ability to bind constitutional elements. Our recent electron microscopic and spectroscopic studies have proved that the sheath comprised an ingenious inorganic/organic hybrid resulting from an interaction between bacterial secretion of exopolymers and deposition of aqueous-phase inorganics such as Fe, phosphorous $(\mathrm{P})$, and silicon $(\mathrm{Si})$ [8-10], providing further insight into the structural and spatial associations among the constitutional elements in the sheath of Leptothrix spp.

Strains of this genus have been successfully isolated and allocated to their taxonomic positions $[3,11,12]$ and several researchers have examined the properties of some of these strains in various culture conditions [13-16]. Our recent findings that the morphological characteristics of the sheaths of Leptothrix sp. strain OUMS1 [12] (hereafter referred to as OUMS1) in the laboratory cultures [8,9] were quite different from those commonly observed among Leptothrix spp. in natural environments $[17,18]$, led us to wonder whether the laboratory conditions accurately reflect the features and modes of bacterial life and the formation of their associated structures in the natural environment. To solve this query, in this paper we devised a unique method of replacing an isolated target strain in natural groundwater conditions.

Using this system, the initial phases from the secretion of bacterial materials to the assembly of the immature sheath skeleton and the subsequent deposition of aqueous-phase inorganic elements were examined in OUMS1 grown in natural groundwater conditions. This study focused on structural and compositional differences and similarities between OUMS1 grown in laboratory and natural conditions. The techniques applied in this study included specific staining by light microscopy, transmission electron microscopy (TEM), scanning electron microscopy (SEM), scanning transmission 
electron microscopy (STEM), STEM-secondary electron imaging (SEI), high-angle annular dark field (HAADF)-STEM, and energy dispersive X-ray (EDX) spectroscopy.

\section{Results and Discussion}

A small bag made of a dialysis tube containing a small aliquot of OUMS1 suspension was found to swell soon after immersion in a container filled with groundwater (Figure 1a). During the 3-day culture period, the bag gradually became yellowish in color, as indicated in Figure 1b. This color did not correlate well with growing OUMS1 cells and their associated sheath structures inside the bag because the native microbes present in the groundwater multiplied on the outer surface of the bag. Tiny coagulations of bacterial cells and immature sheaths became visible within 1 day after immersion of the bag in the groundwater, and gradually turned yellowish-orange by day 2 (Figure 1b). Coagulations of bacterial cells and associated sheaths were visualized in the bag within 1-2 days using a light microscope (Figure 1c). It was thus confirmed that cell population in the bag immersed in groundwater increased from $4.8 \times 10^{4} \mathrm{cfu} / \mathrm{mL}$ on incubation day 0 to $5.2 \times 10^{6} \mathrm{cfu} / \mathrm{mL}$ on day 3 . Furthermore, live/dead staining proved that most bacterial cells were viable (Figure 1d). Furutani et al. [8] reported a similar situation wherein the coexistence of a great number of viable cells and a few dead cells was observed in laboratory conditions. Based on these results, we concluded that the present dialysis tube method did not interfere with OUMS1 survival and its ability to form sheaths.

Figure 1. Dialysis tube bags and light micrographs of growing OUMS1 cells and their associated sheaths in groundwater; (a) A dialysis tube bag containing a small aliquot of a cell suspension swelled immediately after immersion into the container filled with running groundwater; (b) A yellowish-orange-colored bag with coagulated cells and sheaths in the groundwater after 3 days of incubation; (c) A light micrograph of the coagulated cells and sheaths in the groundwater after 3 days of incubation; (d) Green (viable) and red (dead) cells in (c) were detected by specific live/dead staining. Scale bar $=10 \mu \mathrm{m}$ in (c, d).

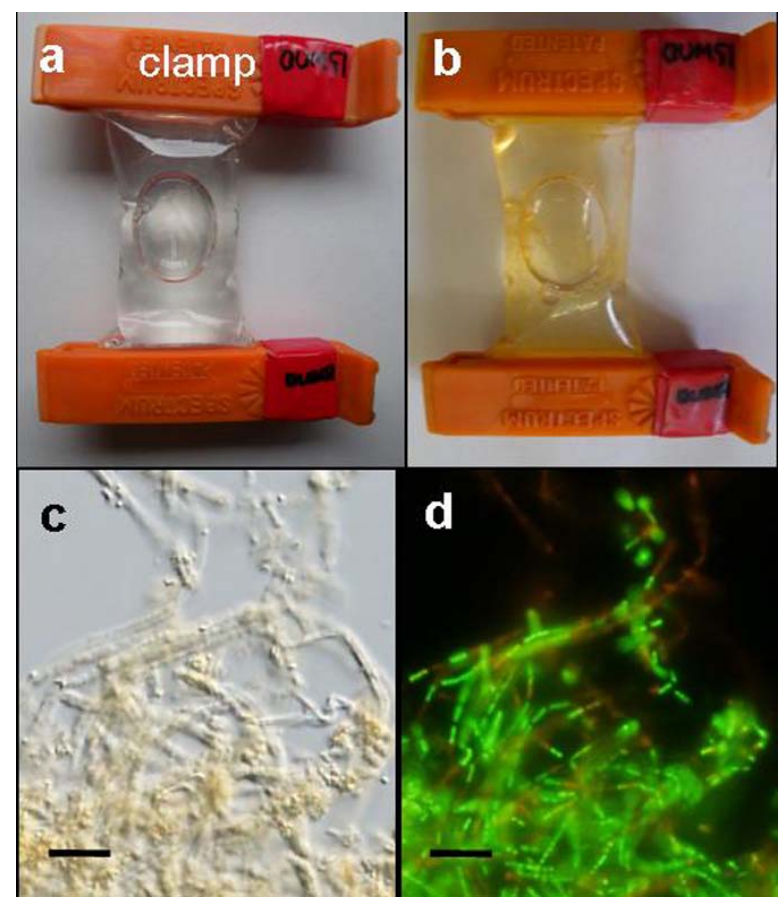


Since this paper focuses on the morphological differences between OUMS1 cells and their associated sheaths formed in medium cultures $[8,9]$ and groundwater cultures, hereafter the former and latter cells and sheaths are referred to as "medium-cell or -sheath" and "groundwater-cell or -sheath," respectively, for simplicity.

Figure 2a shows a SEM image of a medium-sheath from a day 14 culture. It has often been reported that the outer coat of the sheaths of Leptothrix spp. harvested from natural environments is tightly netted with agglutinated thin fibrils [17,18]. By contrast, the outer coat of the medium- and groundwater-sheaths was composed of loosely-woven thin and assembled thick fibrils. As reported by Furutani et al. [8,9], the medium-sheath consisted of a thick homogeneous-looking inner layer 0.3-0.4 $\mu \mathrm{m}$ thick (Figure 2a, iL), which was enclosed by an outer coat of loosely-woven thin and assembled thick fibrils (Figure 2a, oC). By contrast, the groundwater-sheath consisted of a thin heterogeneous-looking inner layer $0.1 \mu \mathrm{m}$ thick (Figure $2 \mathrm{~b}, \mathrm{iL}$ ) and an outer coat of coagulated fibrils with varied thicknesses (Figure $2 b, o C$ ). It is uncertain whether the coagulated feature of the outer coat fibrils reflects the real characteristics because it could have resulted from air-drying of the specimen before SEM observation.

Figure 2. SEM images of a sheath of medium cultures (a) or groundwater (b) at day 14. (a) A sheath with a homogeneous-looking thick inner layer (iL) enclosed with an outer coat (oC) composed of heavily intermingled and coagulated thick fibrils; (b) A sheath with a heterogeneous-looking thin inner layer (iL) enclosed with an outer coat (oC) of intermingled and coagulated thick fibrils. Scale bar $=1 \mu \mathrm{m}$.

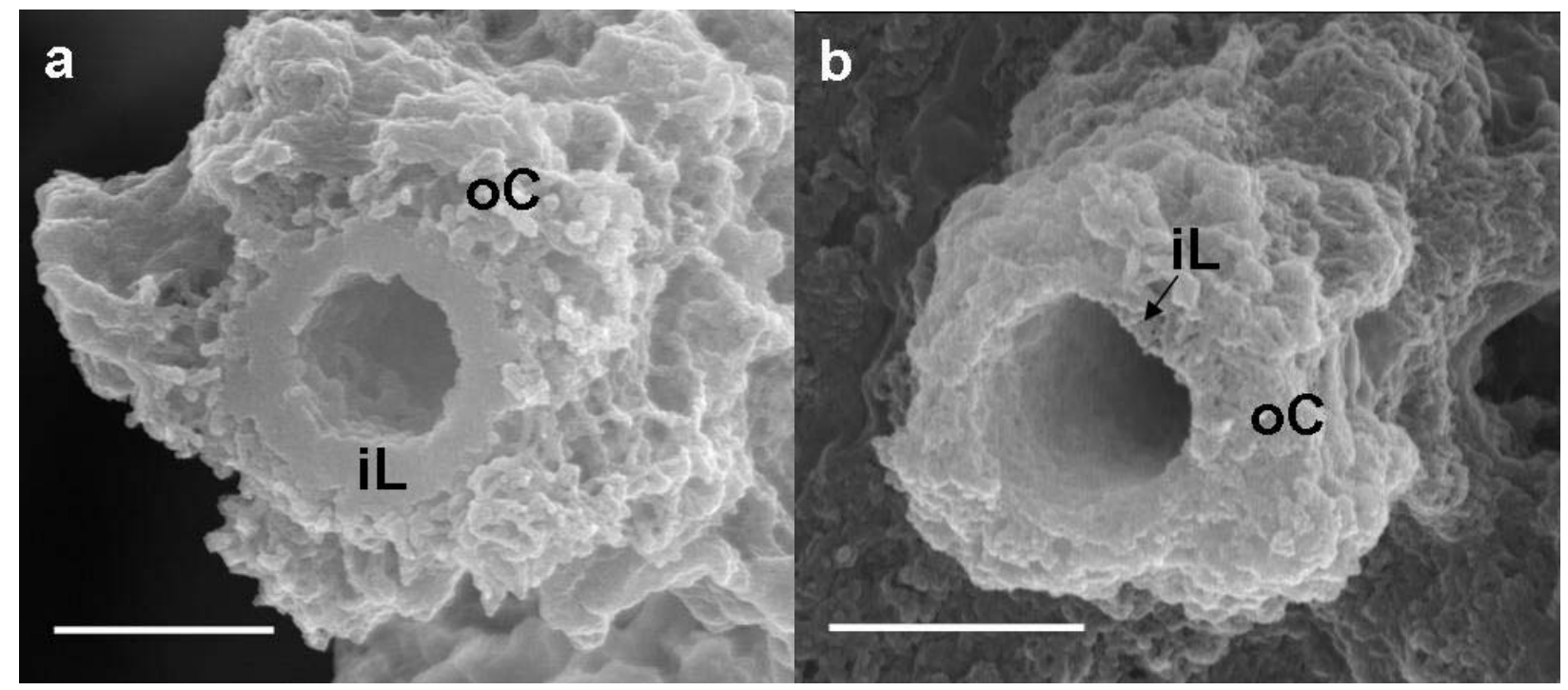

Immediately after harvesting, the medium- and groundwater-sheaths were air-dried on a copper grid covered with a supporting lamella before STEM-SEI and TEM observations. STEM-SEI is formed by a secondary electron beam derived from the specimen surface, whereas TEM images are derived from an electron beam transmitted through the specimen. Therefore, the TEM image is a "shadowgraph" where a transmittable electron builds up a bright image. On comparing medium- and groundwater-sheaths, we observed that the former were almost twice as thick as the latter (Figure 3a, c, note their magnification). Although coagulated fibrils covered both medium- (Figure 3a) and groundwater-sheaths (Figure 3c), 
their entire thickness was much less in the groundwater-sheaths (ca. $10 \mathrm{~nm}$ thick) (Figure 3c, inset) than the medium-sheaths ( $c a .100 \mathrm{~nm}$ thick) (Figure 3a, inset). Figure 3b shows a TEM image of the sheath shown in Figure 3a. Because the medium-sheath has a thick inner layer (Figure 2a), an electron beam at $200 \mathrm{kV}$ was barely transmitted across the entire sheath, so the image was darker, thereby causing only coarse fibrils extending from the sheath edge to be distinguishable (Figure 3b). By contrast, the electron beam was transmitted through the entire groundwater-sheath, giving a bright shadow image that could easily distinguish fine fibrils covering the sheath surface. These TEM images reveal the structural differences in the sheaths indicated by SEM.

Figure 3. STEM-SEI and TEM images of sheaths of medium cultures $(a, b)$ and groundwater cultures $(\mathrm{c}, \mathrm{d})$ at day 14. (a) STEM-SEI image showing a coagulated fibrous outer sheath. The fibrils are 100-200 nm thick (inset); (b) TEM image of (a). The thick inner wall and heavily coagulated outer fibrils blocked transmission of the electron beam, resulting in a dark image; (c) STEM-SEI image showing a coagulated fibrous outer sheath. The fibrils are ca. $10 \mathrm{~nm}$ thick (inset); (d) TEM image of (c) showing a bright image of the entire sheath and fine fibrils in the outer coat. Scale bar $=1 \mu \mathrm{m}$, but $500 \mathrm{~nm}$ in $\mathrm{c}, \mathrm{d}$, and (a) inset and $100 \mathrm{~nm}$ in (c) inset.

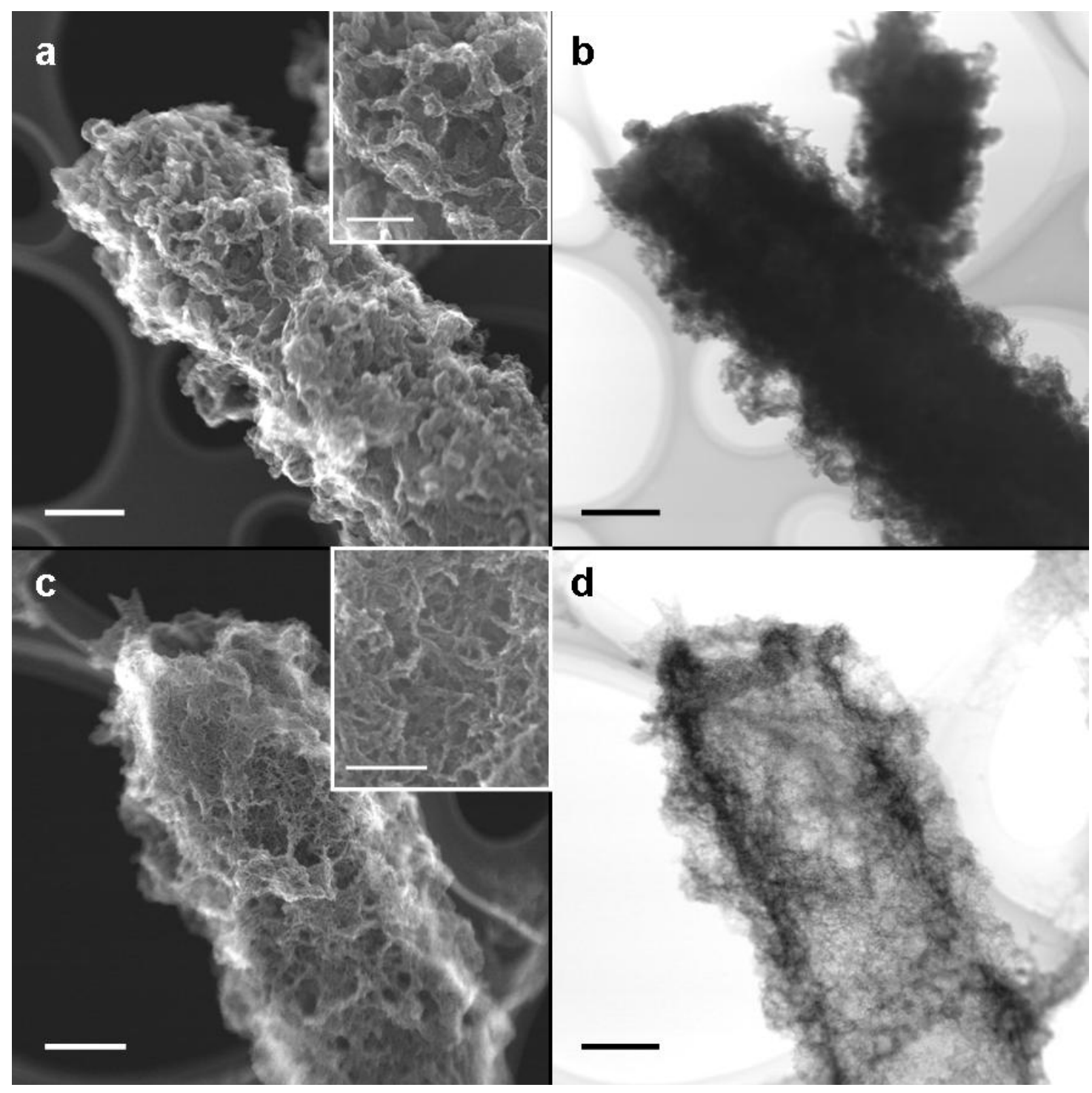


Similar to the medium-cells after 1 day of culture [8.9], some of the groundwater-cells were free of the immature sheath material, while others were surrounded by an extremely thin film corresponding to the immature sheath across the electron-lucent space (Figure 4a, arrows). As often reported in previous analyses of TEM images of a thin-sectioned Leptothrix sp. cell [3], globular protuberances were observed originating from the cell envelope of groundwater-cells (Figure 4a, dotted arrow). Furutani et al. [8] showed by microscopy and specific staining that these carbohydrate-rich protuberances play a role in secretion from cell surfaces and in transportation of saccharic materials to form an immature sheath. As Furutani et al. [9] reported, these protuberances are not membrane-encompassed vesicles, suggesting that they are not formed by the outgrowth of the cell envelope, but rather by the extrusion of saccharic polymers from the cell. At day 2, the features of the immature sheath changed markedly when compared with those at day 1 . The immature groundwater-sheath consisted of a greater number of loosely intermingled fibrils and the entire sheath area increased in thickness (Figure 4b). Compared with the medium-sheath [8,9], the intermingled fibrils appeared coarser, with a lower overall electron density. In the medium-sheath, the inner layer of parallel-lined fibrils was distinguishable from the outer layer of fluffy intermingled fibrils [8,9], whereas in the groundwater-sheath these layers were hardly distinguishable. At day 3 , the entire sheath consisted of densely-intermingled fibrils and electron density was greatly increased, suggesting that aqueous-phase metal ions might have been heavily deposited by this day as was described in previous papers $[8,9]$. Although in some groundwater-sheaths, a less electron-dense innermost layer containing parallel-aligned fibrils could be distinguished (Figure 3a, c, inset, arrow). The inner and outer layers were not clearly distinct in most groundwater-sheaths due to high electron density of the entire sheath area.

Figure 4. TEM images of $\mathrm{U} / \mathrm{Pb}$-stained sections of bacterial cells associated with the immature sheath incubated in the groundwater for 1-3 days. (a) At day 1, protuberances (dotted arrow) originated from the cell envelope and a few fibrous structures of immature sheath (arrow) surrounded the bacterial cell (BC) across the intervening space; (b) At day 2, an immature sheath of intermingled fibrils developed with some electron dense coagulates; (c) At day 3, the immature sheath comprised extremely electron-dense intermingled fibrils, suggesting heavy deposition of aqueous-phase metals. A relatively electron-lucent inner layer of a sheath with parallel-lined fibrils was distinguished in a few sheaths (inset, arrow). Scale bars $=200 \mathrm{~nm}$, but $100 \mathrm{~nm}$ in (c) inset.

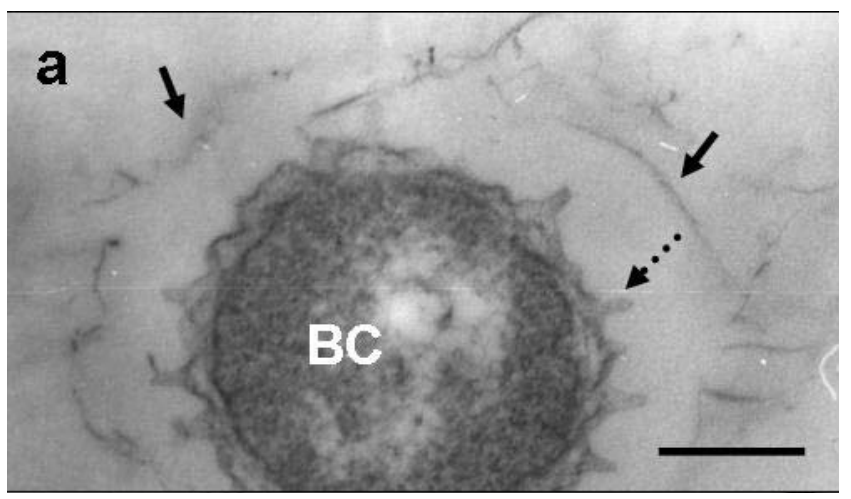


Figure 4. Cont.

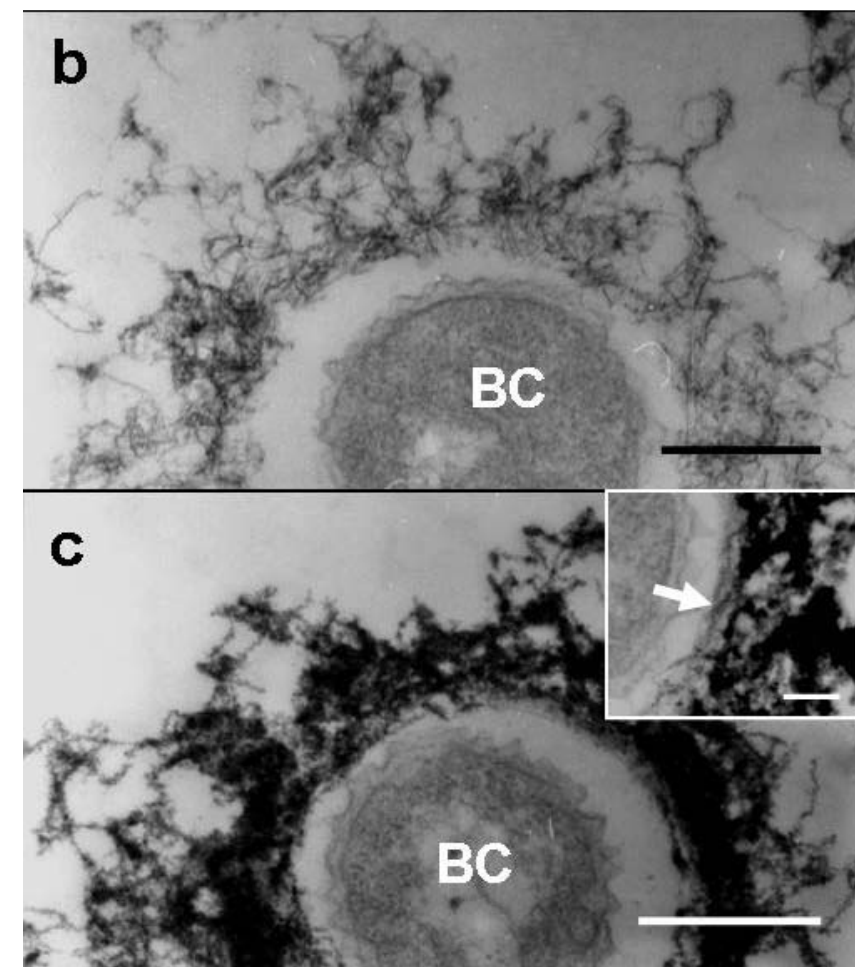

HAADF-STEM imaging and elemental mapping of groundwater-cells/sheaths in combination with a specific carbohydrate stain (alkaline Bi stain) [19] (Supplementary Figure S1) proved that the sheaths had a carbohydrate layer and that Fe was accumulated in the sheath and not the cells as was previously shown [8,9]. Compared with the morphological observation of the medium-cell/sheath reported by Furutani et al. [8,9], culturing of OUMS1 in groundwater led to a formation of sheath architecture having a thinner inner wall layer and an outer coat with finer fibrils. Although further experiments are needed to examine what factors influence the sheath morphology, at present we infer that it can plausibly be attributed to nutritional differences between the systems. Concerning the carbon (C) source, the modified silicon-iron-glucose-peptone (SIGP) medium used in the previous study contained $1 \mathrm{~g} / \mathrm{L}$ each of glucose and peptone [8,9,12], whereas the groundwater in this study contained only $34 \mathrm{mg} / \mathrm{L}$ total C (including $1.4 \mathrm{mg} / \mathrm{L}$ of organic C) (unpublished data). Such nutrition-rich conditions are likely to activate the cells and promote secretion of saccharic materials from the cell envelope, resulting in a thick inner wall of the sheath and thicker fibrils covering the outer coat. Spring [20] noted in his review that reversible or nonreversible loss of physiological and morphological characteristics of pure cultures of strains in the Leptothrix-Sphaerotilus group caused divergent descriptions of species, which were originally described on the basis of such observations. In addition, van Veen et al. [4] noted in their review that sheath formation by this group was greatly affected when the organism was maintained in nutrient-rich conditions. Thus, we should recognize that laboratory culturing of microbes does not always reflect their normal mode of life or the chemical and physical properties of associated structures in the natural environment.

The present dialysis tube method was quite useful for analyzing the reproduction of an isolated strain of aquatic microbes, their mode of production, and the characteristics of their associated 
structures. This system will be used to analyze the behavior of aqueous-phase metal ions with respect to sheath maturation in medium and groundwater conditions.

\section{Experimental Section}

\subsection{Sample and Culturing}

OUMS1 (NITE BP-860) in silicon-iron-glucose-peptone liquid medium lacking $\mathrm{FeSO}_{4}$ (modified SIGP [12]) was incubated on a rotary shaker at $20{ }^{\circ} \mathrm{C}$ and $70 \mathrm{rpm}$ for 2 days. Bacterial cells and associated sheaths were then collected by centrifugation at $4,000 \times \mathrm{g}$ for $10 \mathrm{~min}$. The precipitate was vortexed in sterilized distilled water to disperse maximum number of single cells from their chains and/or sheaths, and $10 \mathrm{~mL}$ of the vortexed sample was transferred into a $50 \mathrm{~mL}$ tube through a 23-gauge needle mounted on a 10-mL syringe to disrupt aggregates [11], followed by filtration with a membrane filter (1.2 $\mu \mathrm{m}$ pore diameter, Millipore Co., Billerica, MA, USA) to remove sheaths and debris. After confirming by light microscopy that the filtrate contained only bacterial cells (although a few cells were still chained) and not sheaths, the filtrate was used as the final bacterial suspension for further cultivation in natural conditions as follows.

To grow OUMS1 in natural conditions, a novel dialysis method was devised as shown in Figure 1. A cellulose dialysis tube (19 mm width, Japan Medical Sci., Takasaki, Japan) was cut into pieces of $15 \mathrm{~cm}$ each. These were then boiled in distilled water at least four times, followed by autoclave sterilization. One end of the tube piece was folded and pinched with a clamp to create a small bag, and $5 \mathrm{~mL}$ of the final bacterial suspension was injected into the bag from which air had been removed. Similarly, the other end of the tube was folded and clamped to create a bag ca. $4 \mathrm{~cm}$ long. The bag was then immersed in a container in which natural groundwater was continuously flowing in and out. A few bags were removed from the container and specimens were prepared every $24 \mathrm{~h}$ until day 3 of culture, and then again on day 14 .

\subsection{Light Microscopy}

The specimens cultured above were observed by differential interference contrast (DIC) microscopy prior to preparation for electron microscopy. The viability of OUMS1 cells in natural conditions was examined by the dilution plate method as follows. The final bacterial suspension described above was serially diluted and spotted onto modified SIGP agar plates. After 3 days of incubation, colonies on the plates were counted with a stereo microscope (day 0 incubation sample). The same protocol to determine the cell numbers was applied to the specimen removed from a dialysis-tube bag incubated in groundwater for 3 days (day 3 incubation sample).

Specimens from the bag were also subjected to a viability test using a bacterial viability kit (LIVE/DEAD $^{\circledR}$ BacLight $^{\mathrm{TM}}$, L7007, Molecular Probes, Eugene, OR, USA) according to manufacturer's protocol (described as live/dead staining above). The specimen was re-suspended in an Eppendorf tube with $0.85 \% \mathrm{NaCl}$ and stained with $1 \mathrm{~mL}$ of the specimen suspension mixed with $3 \mu \mathrm{L}$ of component $\mathrm{A}$ $\left[300 \mu \mathrm{L}\right.$ of a mixture of $\mathrm{SYTO}^{\circledR} 9$ dye $(1.67 \mathrm{mM})$ and propidium iodide $(1.67 \mathrm{mM})$ in Dimethyl sulfoxide (DMSO)] and incubated at room temperature in the dark for $15 \mathrm{~min}$. A small drop of 
the stained specimen was observed by fluorescent microscopy using a U-MWIB3 dichroic mirror unit (460-490 nm excitation filter and $520 \mathrm{~nm}$ emission wavelengths).

\subsection{Electron Microscopy}

The collected samples were washed repeatedly with sterilized ultrapure water and vacuum dried. The dried samples were mounted onto an aluminum specimen stub and vacuum dried for $30 \mathrm{~min}$. After platinum (Pt)-coating, each specimen was observed by SEM (S-4300, Hitachi, Tokyo, Japan). The samples cultured in the modified SIGP liquid medium were treated similarly and observed arbitrarily for reference.

Specimens were collected by centrifugation and fixed with a mixture of $2.5 \%$ glutaraldehyde, $1 \% \mathrm{OsO}_{4}$, and $4.5 \%$ sucrose in $100 \mathrm{mM}$ cacodylate buffer ( $\mathrm{pH} 7.0$ ) on ice for $2 \mathrm{~h}$ and then embedded in 3\% agar. Small pieces of the washed agar block were dehydrated in a graded series of ethanol and again embedded in Quetol 651 resin mixture (Nisshin EM, Tokyo, Japan). Ultrathin sections were stained with uranyl acetate and lead solution (U/Pb-stained sections) and then observed using a TEM (H-7500, Hitachi, Tokyo, Japan) operated at an accelerating voltage of $80 \mathrm{kV}$.

Following the carbohydrate-staining technique devised by Park et al. [19], the ultrathin sections on copper grids were exposed to a 40-fold-diluted alkaline Bi stock solution for $30 \mathrm{~min}$ at $40{ }^{\circ} \mathrm{C}$. The alkaline $\mathrm{Bi}$ stock solution comprised 10\% sodium hydroxide, $4 \%$ potassium sodium tartrate, and $2 \% \mathrm{Bi}$ subnitrate in ultrapure water [19]. After repeated washing with ultrapure water, the grids were observed by TEM (Bi-stained sections).

The $\mathrm{Bi}$ - and $\mathrm{U} / \mathrm{Pb}$-stained ultrathin sections on the copper grids were first covered with a formvar film using a routine method and then coated with $C$ to increase the tolerance of the specimen to an intense electron beam. HAADF-STEM and EDX detectors attached to a JEOL JEM-2100F (accelerating voltage, $200 \mathrm{kV}$ ) TEM were used for HAADF-STEM imaging and mapping of Bi and Fe, respectively. Bright field STEM images were also obtained for reference.

The harvested sheaths from the medium and groundwater cultures were washed repeatedly in distilled water and a suspension was dropped onto a copper grid covered with a C-coated porous thin membrane (NEM, Tokyo, Japan), then air-dried. The specimens were observed by STEM-SEI and TEM.

\section{Conclusions}

In this study, an isolated strain of Leptothrix sp. OUMS1 was cultivated in natural groundwater using a newly-devised dialysis tube method. Its growth and the initial phase of sheath formation were compared with those cultivated continuously in culture medium using an electron microscope. Results demonstrated distinct morphological features of the initial phase of sheath formation in both culture conditions. The present study indicates the ability of the novel dialysis tube method for analyzing the reproduction of an isolated strain of aquatic microbes, their mode of production, and the characteristics of their structures. It also emphasizes that laboratory-cultured microbes do not always reflect the mode of life of the organisms in natural conditions and their associated structures may not possess the same chemical and physical properties as those found in natural conditions. 


\section{Acknowledgments}

This study was financially supported by a Special Grant for Education and Research (2008-2013), a Grant-in-Aid for Research Activity Start-up (No. 22860040, 2010) from the Ministry of Education, Culture, Sports, Science, and Technology, Japan (for J.T.), and a Grant-in-Aid from the Yakumo Foundation for Environmental Science (for T.S.).

\section{References}

1. Ferris, F.G.; Fyfe, W.S.; Beveridge, T.J. Bacteria as nucleation sites for authigenic minerals in a metal-contaminated lake sediment. Chem. Geol. 1987, 63, 225-232.

2. Ghiorse, W.C.; Hirsch, P. An ultrastructural study of iron and manganese deposition associated with extrcellular polymers of pedomicrobium-like budding bacteria. Arch. Microbiol. 1979, 123, 213-226.

3. Ghiorse, W.C. Biology of iron- and manganese-depositing bacteria. Annu. Rev. Microbiol. 1984, $38,515-550$.

4. Van Veen, W.L.; Mulder, E.G.; Deinema, M.H. The Sphaerotilus-Leptothrix group of bacteria. Microbiol. Rev. 1978, 42, 329-356.

5. Knoll, A.H. Life on a Young Planet: The First Three Billion Years of Evolution on Earth; Princeton University Press: Oxfordshire, UK, 2003; p 92.

6. Emerson, D.; Fleming, E.J.; McBeth, J.M. Iron-oxidizing bacteria: An environmental and genomic perspective. Annu. Rev. Microbiol. 2010, 64, 561-583.

7. Fleming, E.J.; Langdon, A.E.; Martinez-Garcia, M.; Stepanauskas, R.; Poulton, N.J.; Masland, E.D.P.; Emerson, D. What's new is old: Resolving the identity of Leptothrix ochracea using single cell genomics, pyrosequencing and FISH. PLoS ONE 2011, 6, 1-16.

8. Furutani, M.; Suzuki, T.; Ishihara, H.; Hashimoto, H.; Kunoh, H.; Takada, J. Assemblage of bacterial saccharic microfibrils in sheath skeleton formed by cultured Leptothrix sp. strain OUMS1. J. Marine Sci. Res. Development. 2011, doi:10.4172/2155-9910.S5-001.

9. Furutani, M.; Suzuki, T.; Ishihara, H.; Hashimoto, H.; Kunoh, H.; Takada, J. Initial assemblage of bacterial saccharic fibrils and element deposition to form an immature sheath in cultured Leptothrix sp. strain OUMS1. Minerals 2011, 1, 157-166.

10. Suzuki, T.; Hashimoto, H.; Ishihara, H.; Kasai, T.; Kunoh, H.; Takada, J. Structural and spatial associations between $\mathrm{Fe}, \mathrm{O}$, and $\mathrm{C}$ in the network structure of the Leptothrix ochracea sheath surface. Appl. Environ. Microbiol. 2011, 77, 7873-7875.

11. Emerson, D.; Ghiorse, W.C. Isolation, cultural maintenance, and taxonomy of a sheath-forming strain of Leptothrix discophora and characterization of manganese-oxidizing activity associated with the sheath. Appl. Environ. Microbiol. 1992, 58, 4001-4010.

12. Sawayama, M.; Suzuki, T.; Hashimoto, H.; Kasai, T.; Furutani, M.; Miyata, N.; Kunoh, H.; Takada, J. Isolation of a Leptothrix strain, OUMS1, from ocherous deposits in groundwater. Curr. Microbiol. 2011, 63, 173-180. 
13. Boonfueng, T.; Axe, L.; Yee, N.; Hahn, D.; Ndiba, P.K. Zn sorption mechanisms onto sheathed Leptothrix discophora and the impact of the nenoparticulate biogenic $\mathrm{Mn}$ oxide coating. J. Colloid Interface Sci. 2009, 333, 439-447.

14. Emerson, D.; Ghiorse, W.C. Ultrastructure and chemical composition of the sheath of Leptothrix discophora SP-6. J. Bacteriol. 1993, 175, 7808-7818.

15. Emerson, D.; Ghiorse, W.C. Role of disulfide bonds in maintaining the structural integrity of the sheath of Leptothrix discophora SP-6. J. Bacteriol. 1993, 175, 7819-7827.

16. Takeda, M.; Makita, H.; Ohno, K.; Nakahara, Y.; Koizumi, J. Structural analysis of the sheath of a sheathed bacterium, Leptothrix cholodnii. Int. J. Biol. Macromol. 2005, 37, 92-98.

17. Hashimoto, H.; Yokoyama, S.; Asaoka, H.; Kusano, Y.; Ikeda, Y.; Seno, M.; Takada, J.; Fujii, T.; Nakanishi, M.; Murakami, R. Characteristics of hollow microtubes consisting of amorphous iron oxide nanoparticles produced by iron oxidizing bacteria, Leptothrix ochracea. J. Magn. Magn. Mater. 2007, 310, 2405-2407.

18. Sakai, T.; Miyazaki, Y.; Murakami, A.; Sakamoto, N.; Ema, T.; Hashimoto, H.; Furutani, M.; Nakanishi, M.; Fujii, T.; Takada, J. Chemical modification of biogenous iron oxide to create an excellent enzyme scaffold. Org. Biomol. Chem. 2010, 8, 336-338.

19. Park, P.; Ohno, T.; Kato-Kikuchi, H.; Miki, H. Alkaline bismuth stain a tracer for Golgi vesicles of plant cells. Stain Technol. 1987, 62, 253-256.

20. Spring, S. The genera Leptothrix and Sphaerotilus. The Prokaryotes 2006, 5, 758-777.

(C) 2012 by the authors; licensee MDPI, Basel, Switzerland. This article is an open access article distributed under the terms and conditions of the Creative Commons Attribution license (http://creativecommons.org/licenses/by/3.0/). 